\title{
İnsan Bilgisayar Etkileşimi ile Proprioseptif Duyuların Geliştirilmesi
}

\author{
Uğur Fidan ${ }^{1 *}$, Mehmet Yildız ${ }^{2}$, Aslıhan Şahan ${ }^{3}$ \\ ${ }^{1}$ Afyon Kocatepe Üniversitesi, Mühendislik Fakültesi, Biyomedikal Mühendisliği Bölümü, Afyonkarahisar, Türkiye (ORCID: 0000-0003-0356-017X) \\ ${ }^{2}$ Afyon Kocatepe Üniversitesi, Beden Eğitimi ve Spor Yüksek Okulu, Antrenörlük Bölümü, Afyonkarahisar, Türkiye (ORCID: 0000-0003-3481-7775) \\ ${ }^{3}$ Afyon Kocatepe Üniversitesi, Mühendislik Fakültesi, Biyomedikal Mühendisliği Bölümü, Afyonkarahisar, Türkiye (ORCID: 0000-0002-2102-1164)
}

(Bu yayın HORA'da sözlü olarak sunulmuştur.)

(İlk Geliş Tarihi 1 Ağustos 2019 ve Kabul Tarihi 24 Ekim 2019)

(DOI: 10.31590/ejosat.637808)

ATIF/REFERENCE: Fidan, U., Yıldız, M. \& Şahan, A. (2019). İnsan Bilgisayar Etkileşimi ile Proprioseptif Duyuların Geliştirilmesi. Avrupa Bilim ve Teknoloji Dergisi, (Özel Say1), 177-184.

\section{$\ddot{O} \mathbf{z}$}

Dış ortamdan gelen kuvvetlere karşı kararlı hareketler yapabilme veya vücut postürünün korunmasından sorumlu olan denge yön değiştirme, durma, tutma, nesneyi hareket ettirme vb. kinetik ve kinematik hareketleri kontrol etmektedir. Bu hareketler görsel, verstibüler ve proprioseptif sistemlerden alınan verilerin beyin denge merkezinde işlenmesi ile sağlamaktadır. Kas, eklem ve tendonlarda bulunan mekanoreseptörlerin değişen pozisyon, durum ya da güçleri algılaması ile başlayan proprioseptif sistem vücudun ve uzuvların konumunun beyin tarafından algılanmasına yardımcı olur. Herhangi bir rahatsızlık nedeni ile fizik tedavi ve rehabilitasyona ihtiyaç duyan hastalar veya üst düzey performans göstermesi gereken sporcuların hareket yeteneklerini geliştirmek için farklı tedavi ve egzersiz programları bulunmaktadır. Günümüzde gelişmekte olan insan bilgisayar etkileşim (HMI) araçları her alanda olduğu gibi fizik tedavi ve rehabilitasyon ile spor alanında da kullanılmaya başlanmıştır. Bu çalışma, propriyoseptif duyularının geliştirilmesi ve gelişimin süreceinin takip edelebildiği bir ölçüm sistemini gerçekleştirmeyi amaçlamaktadır. Gerçekleştirilen sistem donanım, mekanik ve yazılım olmak üzere üç temel bölümden oluşmaktadır. Kişinin denge merkezinden sapmasını ölçen Zemic L6E kuvvet sensörü ile alınan veriler seri senkron haberleşme ile mikrodenetleyiciye aktarılır. Aktarılan veriler denetleyici yazılımı ile kuvvet değerleri hesaplanarak kablosuz haberleşme modülü üzerinden PC yazılımına gönderilir. PC' ye aktarılan veriler işlenerek Unity oyun motorunda tasarlanan oyunlarda cisimleri yönlendirmek için kullanılmıştır. Böylece kişilerin proprioseptif duyularının geliştirilmesi için oyun tabanlı bir egzersiz sistemi oluşturulmuştur. Geliştirilen sistem ile bireyin ağırlık merkezinin frontal ve lateral eksenlerdeki sapması ölçülmüştür. Sağlıklı bir bireyin $30 \mathrm{~s}$ test süresince frontal eksende $\pm 1^{\circ}$, lateral eksende $\pm 1^{\circ}$ salınım yaptığı görülmüştür. Geliştirilen ölçüm ve egzersiz programı ile sağlıklı bir birey programın uygulama takvimine bağlı kalınarak çalıştırılmıştır. Egzersiz programı sonunda frontal ve

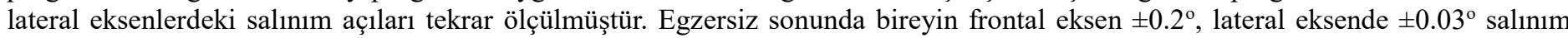
yaptığı görülmüştür. Elde edilen sonuçlar proprioseptif duyuların insan bilgisayar etkileşim araçları ile hem ölçülebileceği hem de geliştirilebileceğini göstermektedir.

\section{Development of Proprioceptive Senses by Human Machine Computer Intercation}

\begin{abstract}
Balance that is responsible for maintaining stable movements against external forces or maintaining body posture; change direction, stop, hold, move the object and so on. controls kinetic and kinematic movements. These movements provide visual, verstibular and proprioceptive systems by processing the data in the brain balance center.The proprioceptive system, which starts with the mechanoreceptors in the muscles, joints and tendons, perceives changing positions, states or forces, helps the brain to perceive the
\end{abstract}

\footnotetext{
* Sorumlu Yazar: Afyon Kocatepe Üniversitesi, Mühendislik Fakültesi, Biyomedikal Mühendisliği Bölümü, Afyonkarahisar, Türkiye, ORCID: 00000003-0356-017X, ufidan@aku.edu.tr
} 
position of the body and limbs. There are different treatment and exercise programs to improve the mobility of the patients who need physical therapy and rehabilitation due to any discomfort or the athletes who need to perform at high level.Today, developing human computer interaction (HMI) tools are being used as in all areas, physical therapy and rehabilitation as well as in sports. This study aims to develop a proprioceptive senses and to realize a measurement system in which the progress of development can be followed. The system consists of three basic parts: hardware, mechanical and software. The data received by the Zemic L6E force sensor which measures the deviation from the center of balance of the person is transferred to the microcontroller via serial synchronous communication. The transmitted data is sent to the PC software via wireless communication module by calculating the force values with the controller software. The data transferred to the PC were processed and used to manipulate objects in games designed in the Unity game engine. Thus a person of game-based exercise system was created for the development of proprioceptive sense. The deviation of the center of gravity of the individual on the frontal and lateral axes was measured with the developed system. A healthy individual oscillated $\pm 1^{\circ}$ on the frontal axis and $\pm 1^{\circ}$ on the lateral axis during the $30 \mathrm{~s}$ test. With the developed measurement and exercise program, a healthy individual was employed by adhering to the application schedule of the program. At the end of the exercise program, oscillation angles in the frontal and lateral axes were measured again. At the end of the exercise, it was observed that the individual oscillated $\pm 0.2 \mathrm{o}$ in the frontal axis and $\pm 0.03 \mathrm{o}$ in the lateral axis. The results show that proprioceptive senses can be measured and improved by human computer interaction tools.

Keywords: Lower extremity, Balance, Proprioceptive Sense, Unity, Game Based Exercise

\section{Giriş}

Tüm vücudun koordineli şekilde hareket edebilmesi denge becerisiyle doğru orantılı olarak gerçekleşir. Dengenin kontrolü, duyusal girdilerin bütünleşmesi yanında esnek hareket şekillerinin planlanması ve uygulamasını içeren karmaşık bir motorik beceridir. Bireyler vücudun dengesini görsel, verstibüler ve Proprioseptif sistemlerden alınan veriler ile sağlamaktadır. Kas, eklem ve tendonlarda bulunan mekanoreseptörlerin değişen pozisyon, durum ya da güçleri algılaması ile başlayan proprioseptif sistem vücudun ve uzuvların konumunun beyin tarafindan algılanmasına yardımcı olur. Herhangi bir rahatsızlık nedeni ile fizik tedavi ve rehabilitasyona ihtiyaç duyan hastalar veya üst düzey performans göstermesi gereken sporcuların hareket yeteneklerini geliştirmek için farklı tedavi ve egzersiz programları bulunmaktadır. Günümüzde gelişmekte olan insan bilgisayar etkileşim (HMI) araçları her alanda olduğu gibi fizik tedavi ve rehabilatasyon ile spor alanında da kullanılmaya başlanmıştır.

Konu ile ilgili literatür incelendiğinde; 2016 yılında Erdoğan ve arkadaşları dinamik ve statik denge egzersizlerinin alt ekstremite üzerindeki etkilerini araştırmıştır. Çalışmalarında deneklere dinamik denge ölçümü için yıldız denge testi ve statik denge ölçümü için flamingo denge testi uygulanmıştır. Çalışma sonucunda denge egzersizlerinin alt ekstremite kas stabilizasyonunu arttırdığ 1 ve statik denge egzersizlerinin dinamik denge egzersizlerine göre denge performansı üzerinde daha etkili olduğu kanıtlanmıştır (Ceren Suveren Erdoğan et al. 2016). 2017 yılında Ateş ve arkadaşlarını yaptığı çalışma, denge antrenmanlarının sakatlık sonrası rehabilitasyon programının bir parçası olarak veya sportif performansı arttırmak için uygulandığını göstermektedir (Bahar Ateş et al. 2017). 2018 yılında Demir ve arkadaşlarının yaptığı çalışmada ise nintendo wii video oyunu ile wobble board denge antrenmanlarının statik denge gelişimleri üzerine etkisini karşılaştırmıştır. Araştırma sonrasında hem wobble board hem de nintendo wii video oyunlarının çocuklarda statik dengeyi geliştirdiğini saptanmıştır. $\mathrm{Bu}$ araştırma aktif video oyunlarının denge antrenmanları kadar etkili olduğunu göstermektedir. Bu bağlamda aktif video oyunları dengeyi geliştirmek için alternatif bir yöntem olarak araştırmacılar tarafından önerilmektedir. (Abdurrahman Demir et al. 2018). Konu ile ilgili yapılan çalışmalar incelendiğinde proprioseptif duyuların geliştirilebileceğini göstermekle birlikte bu sistemlerin tasarımı ve gerçekleştrilmesi üzerine yapılan çalışmaların yetersiz olduğunu göstermektedir. Denge ölçümü için kliniklerin denge merkezinde bulunan posturografi cihazlarından yararlanılmaktadır. Bu sistemler pahalı ve denge ölçümüne yönelik olup bünyesinde egzersiz ile gelişim modülleri bulunmamaktadır.

Günümüzde oyun oynama fikri pek çok alanda kullanılmakta ve bu sayede zorlanarak ya da sıkılarak yapılan uygulamalar daha eğlenceli hale getirilebilmektedir. Bu çalışma, üst düzey denge ve hareketliliğe ihtiyaç duyan profesyonel sporcular veya herhangi bir rahatsızlık sonucunda fizik tedavi ve rehabilitasyona ihtiyaç duyulan hastalar için proprioseptif duyuların yeterliliğini ölçmeyi ve tasarlanan oyunlar ile bu duyuları geliştirmeyi amaçlamaktadır.

\section{Materyal ve Metot}

\subsection{Denge ve Duyu Sistemleri}

Şekil 1'de vücut denge mekanızması ve görsel, verstibüler ve propriseptif duyularının denge üzerindeki etki oranları görülmektedir. Şekil 1b'de görüldüğü üzere vücut dengesinin sağlanmasında proprioseptif sistemin daha etkili olduğu görülmektedir. Proprioseptif sistem, ilk olarak mekanoreseptörlerin değişen pozisyon, durum ya da güçleri algılaması ile başlamkatadır. Mekanoreseptörler, içerisinde sinir dokusu bulunan tüm dokularda bulunurlar. Yapılan histolojik çalışmalar farklı mekanoreseptörlerin varlığını ortaya koymaktadır. En çok bilinenleri ruffini sonlanmaları, pacinian cisimcikleri, golgi tendon organ reseptörleri, kas iğciği olarak özetlenebilir. (Haydar Kaynak et al. 2015). 


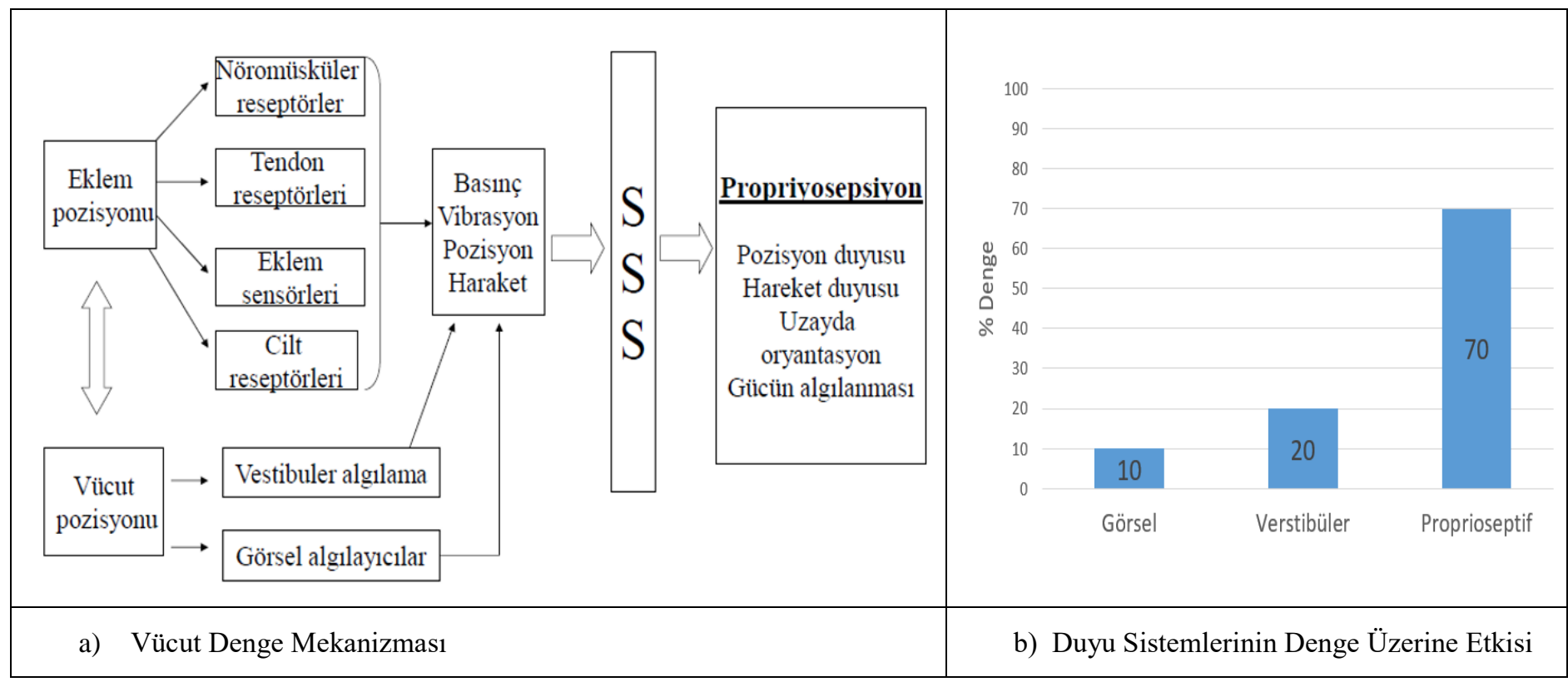

Şekil 1. Denge Mekanizmast ve Duyu Sistemlerinin Etkisi

Mekanoreseptörler her dokuda farklı oranlarda bulunmaktadır. Örneğin tendonlarda ki gerilimi algılayan golgi tendon organı tendon bölgelerinde daha yoğun bulunmaktadır. Ağırlık kaldırıldığında, golgi tendon organı kasın ne kadar gergin olduğunu göstermektedir. Çok fazla kas gerginliği varsa, golgi tendon organı refleks yayı ile kasın herhangi bir kuvvet yaratmasını engeller ve bu sayede kas iskelet sistemini yaralanmalara karşı korur. Kas dokusu içerisinde bulunan kapsüllü yapıdaki kas iğcikleri kas lifinin gerilme ve kısalmasına karşı duyarlıdır. Aktif veya pasif şekilde kasta oluşan gerilim değişimlerini santral sinir sistemine iletirler ve özel reflekslerin ortaya çıkmasını sağlar.

\section{2. Ölçüm Egzersiz Sistemi}

Şekil 2'de proprioseptif duyuların yeterliliklerini ölçen ve proprioseptif duyuları egzersiz ile geliştirmeyi sağlayan sistemin genel blok diyagramı görülmetedir. Gerçekleştirilen sistem mekanik, donanım ve yazılım olmak üzere üç temel bölümden oluşmaktadır. Mekanik sistemin 4 bir yanına yerleştirilen Zemic L6E kuvvet sensörleri ile vücudun ağırlık merkezindeki sapması ölçülmektedir. Ölçülen bu değerler I2C protokü üzerinden mikrodenetleyiciye aktarılır. Aktarılan veriler denetleyici yazılımı ile kutuısal forma dönüştürülerek merkezden olan sapma ve sapma açı değerlerine dönüştürülür. Kutupsal formadaki bu veriler $2.4 \mathrm{GHz}$ çalışma frekanslı bluetooth 2.0 üzerinden PC yazılımına gönderilir. PC' ye aktarılan veriler Unity3D oyun motorunda hazırlanmış oyunlardaki imleçlerin kontrolünü sağlamaktadır.

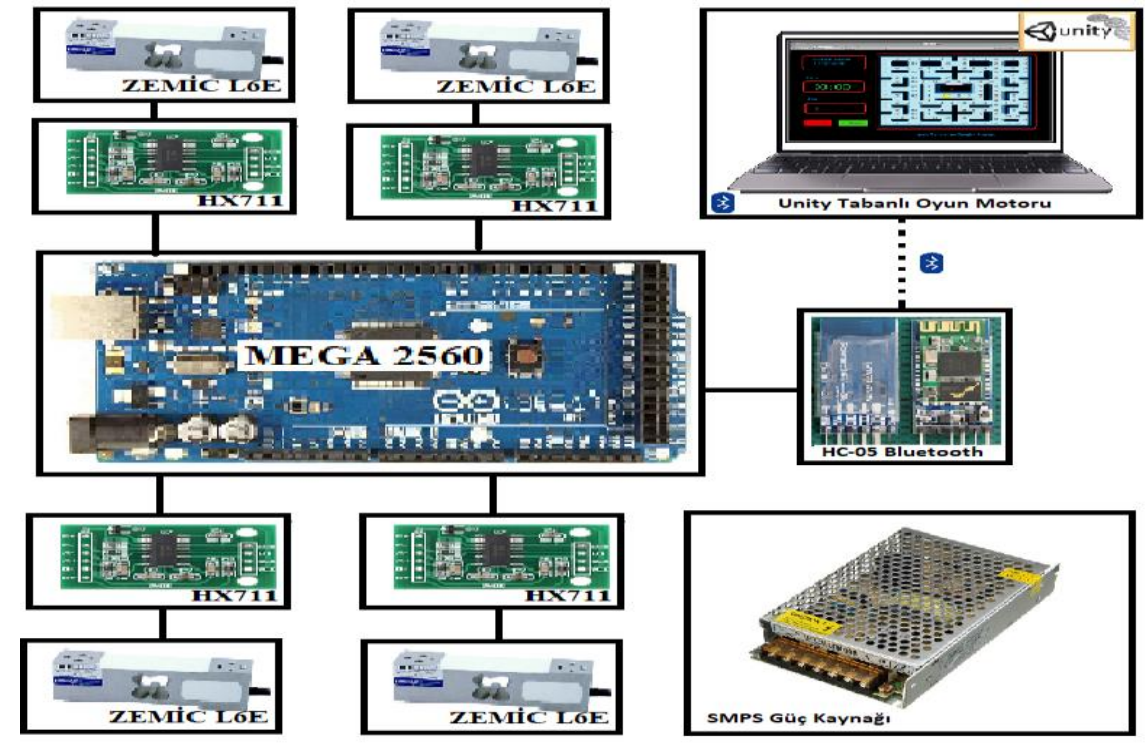

Şekil 2. Proprioseptif Duyuların Geliştirilmesi İçin Egzersiz ve Ölçüm Sistemi Blog Diyagramı

\subsubsection{Yük Hücresi}


Şekil 3'de genel yapısı görülen yük hücresi üzerine uygulanan kuvveti elektrik sinyaline çevirmektedir. Hidrolik, pnömatik ve gerinim ölçerler gibi çeşitli yük hücre tipleri bulunmaktadır. Gerinim ölçer yük hücreleri, yük hücrelerinin elastik malzemesi uygun biçimde deforme olduğunda bu deformeye bağlı olarak gerinim ölçerde de gerinime neden olur. Bu deforme sonucu düzlemsel olarak oluşturulmuş hassas yüzeydeki direnç telleri uzayıp kısalarak direnç değişikliği oluşmaktadır. Gerinim ölçerin deformasyonu, uygulanan kuvvetle orantılı elektrik sinyallerine dönüştürülür (İnt.Kyn.6). Bu çalışmada kişinin denge durumunun ölçümünde platform tipi, alüminyum alaşımlı, IP65 koruma sınıfına sahip 200 kg kapasiteli Zemic L6E yük hücresi kullanılmıştır (İnt.Kyn.16).

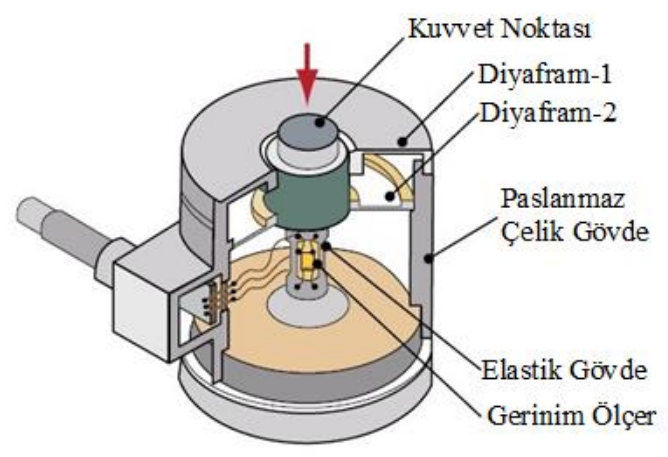

Şekil 3. Yük hücresi

\subsubsection{HX 711Yük Hücre Yükselteci}

Yük hücreleri, kesiti çok küçük iletken bir telin çok ince bir şerit üzerine tekrarlı sarımlar şeklinde yerleştirilmesinden oluşmaktadır. Temelde bir direnç olan bu sensörün görevi yüzeyin uzama miktarını ölçmektir. Kuvvet uygulandığında gerinim ölçerlerin üzerindeki tellerin çapı da yapıştırılan parçanın uzaması ile birlikte değişmektedir. Direnci değişen tellerin üzerinden geçen akımda değişmektedir. Bu çalışma prensibine göre değişen akım değeri Wheatstone köprüsü ile hassas bir şekilde ölçülebilmektedir. Şekil 4'de yük hücresinin ölçüm devresi görülmektedir. Devrede kullanılan HX711 entegre bünyesinde 24bit çözünürlüklü diferansiyel ADC bulunmaktadır. Saniyede 80 adet ölçümü dijital veriye dönüştürüp I2C protokolü üzerinden mikrodenetleyici devresine aktarmaktadır.

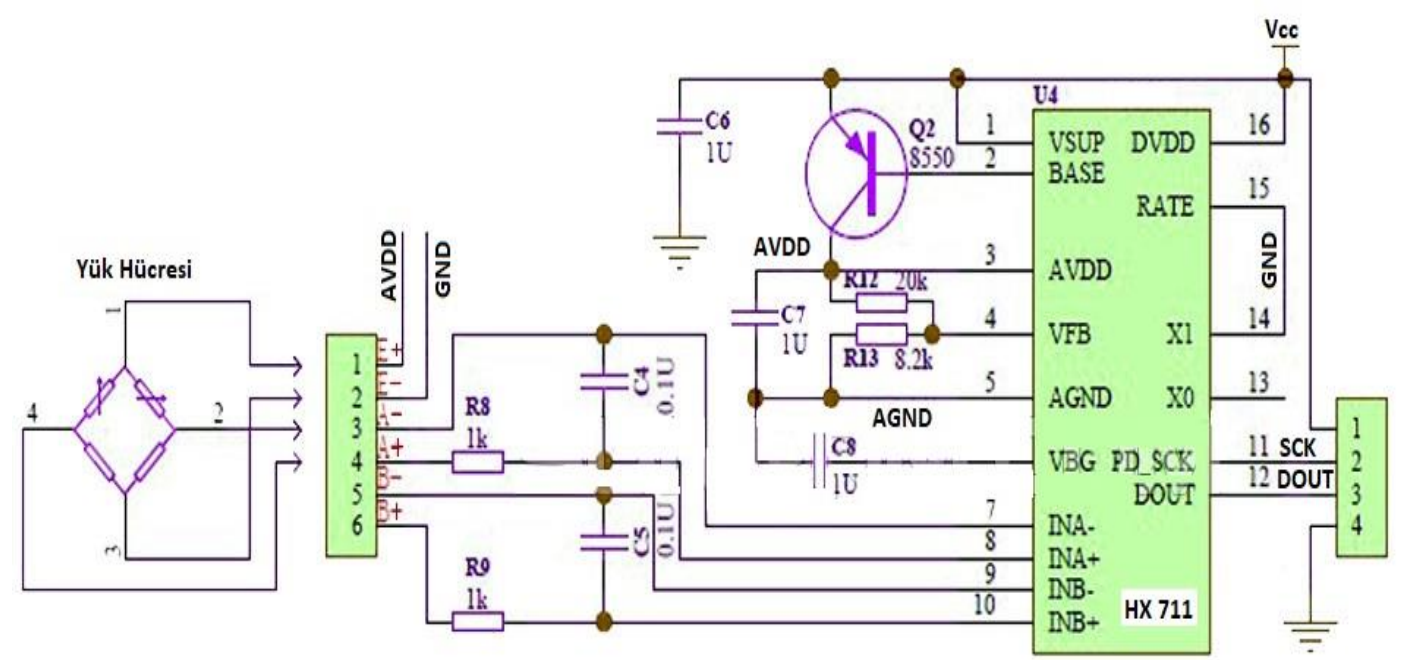

Şekil 4. HX711 Devre Şeması

\subsection{Egzersiz Programı}

Tablo 1'de ölçüm ve egzersiz program içeriği görülmektedir. Geliştirilen içerik test, statik egzersiz ve dinamik egzersiz olmak üzere 3 bölümden oluşturulmuştur. Şekil 5'de ölçüm ve egzersiz programının uygulanması için 20 bölümden oluşturulan uygulama takvimi görülmektedir. Programdaki herbir bölüm statik ve dinamik olmak üzere 6 farklı aktivite içermektedir. Program bölümleri kolaydan zora doğru derecelendirilmiştir. Programın hafta içi hergün hafta sonları ise bireylerin kendi yaşam alanlarıdaki egzersizler ile tamamlaması planlanmıştır. Programın ilk bölümü statik ve dinamik postür testlerini içermekte olup her 5 bölümde bir test tekrarlanarak gelişim sürecinin takibi sağlanmıştır. Elde edilen veriler Access veri tabanında tutularak program sonunda raporlanmıştır.

Tablo 1. Çalışmada Kullanılan Ölçüm ve Egzersiz Program Iç̧eriği 
European Journal of Science and Technology

\begin{tabular}{|c|c|c|c|}
\hline Sira & Test & $\begin{array}{c}\text { Statik Egzersiz } \\
\end{array}$ & Dinamik Egzersiz \\
\hline 1 & $\begin{array}{l}\text { Göz açık iken imlecin sagittal } \\
\text { eksende 30s sabit tutulmas }\end{array}$ & İmleci (Göz açık) merkezde tutma & Hareketli nesneyi imleç ile takip etme \\
\hline 2 & $\begin{array}{l}\text { Göz kapalı iken imleci } \\
\text { merkezde 30s sabit tutulması }\end{array}$ & $\begin{array}{l}\text { İmleci (Göz açı) sünger zemin } \\
\text { üzerinde merkezde tutma }\end{array}$ & $\begin{array}{l}\text { Hareketli nesneyi imleç ile sünger zemin } \\
\text { üzerinde takip etme }\end{array}$ \\
\hline 3 & $\begin{array}{l}\text { Göz açık iken lateral ve } \\
\text { anterior eksenlerede } 6 \text { derece } \\
\text { posterior eksende } 4.5 \text { derece } \\
\text { hareketli nesne takibi }\end{array}$ & $\begin{array}{l}\text { İmleci (Göz açık) çim halı zemin } \\
\text { üzerinde merkezde tutma }\end{array}$ & $\begin{array}{l}\text { Hareketli nesneyi imleç ile çim halı } \\
\text { üzerinde takip etme }\end{array}$ \\
\hline 4 & & $\begin{array}{l}\text { İmleci (Göz açık) imleci pürüzlü zemin } \\
\text { üzerinde merkezde tutma }\end{array}$ & $\begin{array}{l}\text { Hareketli nesneyi imleç ile pürüzlü } \\
\text { zemin üzerinde takip etme }\end{array}$ \\
\hline 5 & & Göz kapalı imleci merkezde tutma & $\begin{array}{l}\text { Hareketli nesneyi imleç ile takip etme } \\
\text { (Sağ el topu havaya atıp yakalama) }\end{array}$ \\
\hline 6 & & $\begin{array}{l}\text { Göz kapalı imleci sünger zemin } \\
\text { üzerinde merkezde tutma }\end{array}$ & $\begin{array}{l}\text { Hareketli nesneyi imleç ile takip etme } \\
\text { (Sol el topu havaya atıp yakalama) }\end{array}$ \\
\hline 7 & & $\begin{array}{l}\text { Göz kapalı imleci çim halı zemin } \\
\text { üzerinde merkezde tutma }\end{array}$ & $\begin{array}{l}\text { Hareketli nesneyi imleç ile takip etme } \\
\text { (Her iki eldeki topu yerdeğiştirme) }\end{array}$ \\
\hline 8 & & $\begin{array}{l}\text { Göz kapalı imleci pürüzlü zemin } \\
\text { üzerinde merkezde tutma }\end{array}$ & $\begin{array}{l}\text { Hareketli nesneyi imleç ile takip etme } \\
\text { (Eldeki üç topu çevirme) }\end{array}$ \\
\hline 9 & & $\begin{array}{l}\text { İmleci (Göz açık) merkezde tutma (Sağ } \\
\text { el topu havaya atıp yakalama) }\end{array}$ & $\begin{array}{l}\text { Balon Patlatma Oyununun alt postür ile } \\
\text { kontrol edilmesi }\end{array}$ \\
\hline 10 & & $\begin{array}{l}\text { İmleci (Göz açık) merkezde tutma (Sol } \\
\text { el topu havaya atıp yakalama) }\end{array}$ & $\begin{array}{l}\text { Pacman'nin alt postür ile kontrol edilmesi } \\
\text { ve karşıdan gelen topu yakalayıp geri } \\
\text { verilmesi }\end{array}$ \\
\hline 11 & & $\begin{array}{l}\text { İmleci (Göz açık) merkezde tutma (Her } \\
\text { iki eldeki topu yerdeğiştirme) }\end{array}$ & $\begin{array}{l}\text { Pacman'nin alt postür ile kontrol edilmesi } \\
\text { ve eldeki iki topun çevrilmesi }\end{array}$ \\
\hline 12 & & $\begin{array}{l}\text { İmleci (Göz açık) merkezde tutma } \\
\text { (Eldeki üç topu çevirme) }\end{array}$ & \\
\hline
\end{tabular}

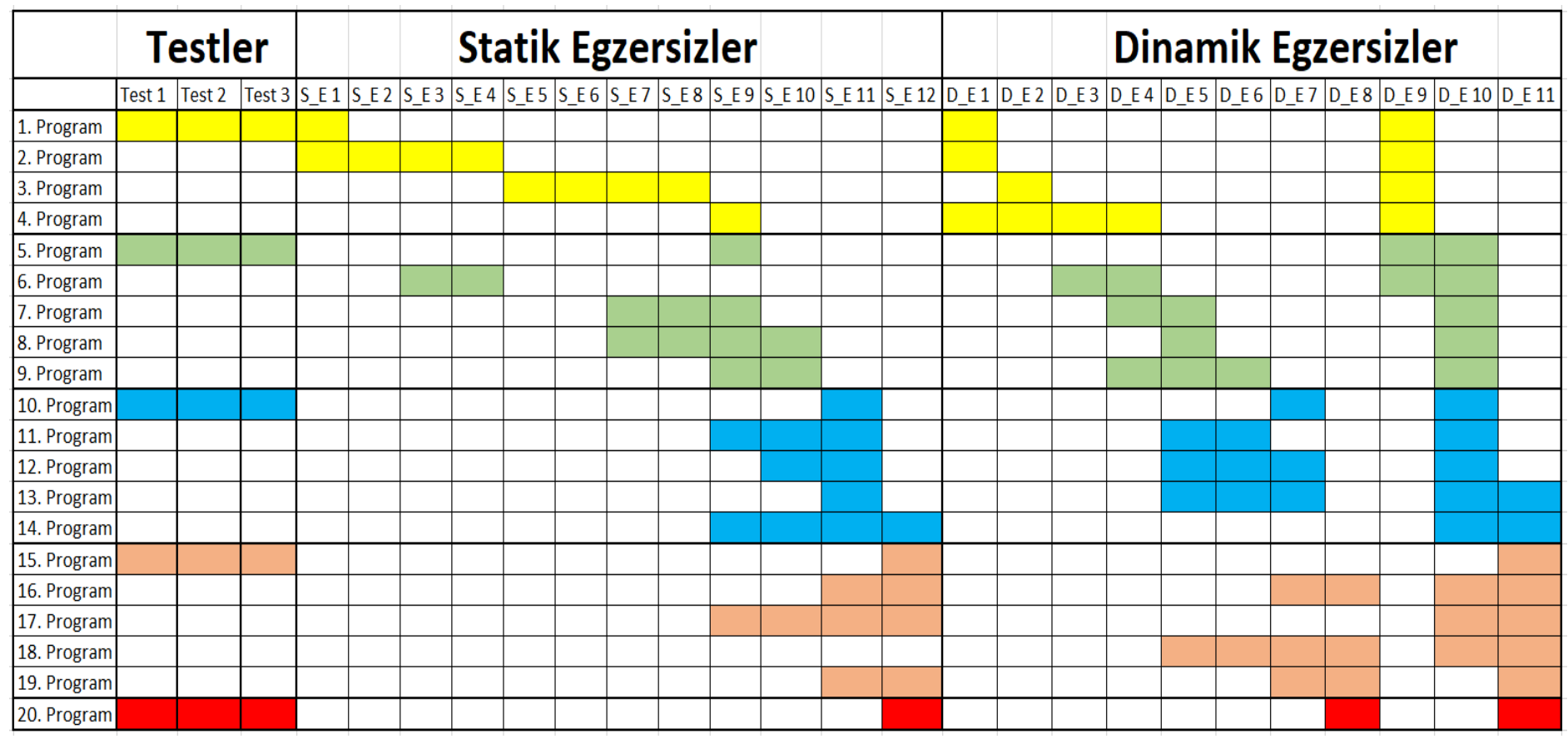

Şekil 5. Ölçüm ve Egzersiz Programı 
Şekil 6'da gerçekleştirilen sistemin genel yapısı görülmektedir. Geliştirilen sistem proprioseptif duyuların yeterliliklerinin ölçülmesini sağlandığ gibi geliştirilen oyunlar ile kişinin proprioseptif duyularının geliştirilmesi için oyun tabanlı bir egzersiz sistemine dönüştürülmüştür. Arayüz yazılımı ile denge ölçüm sistemi arasında kablosuz bağlantı kurulduktan sonra ölçüm veya egzersiz modu seçilir. Egzersiz modunda süre sınırlaması olmaksızın antrenman yapılır. Ölçüm modunda 30s süresi içerisinde alt ekstremitenin statik veya dinamik dengesi ölçülür. Ölçülen veriler analiz edilmek üzere Access veri tabanına kayıt edilir. Lateral düzlem için balon patlatma ve lateral - frontal düzlemler için pacman oyunları unity oyun motoru ile tasarlanarak sisteme entegrasyonu sağlanmıştır.

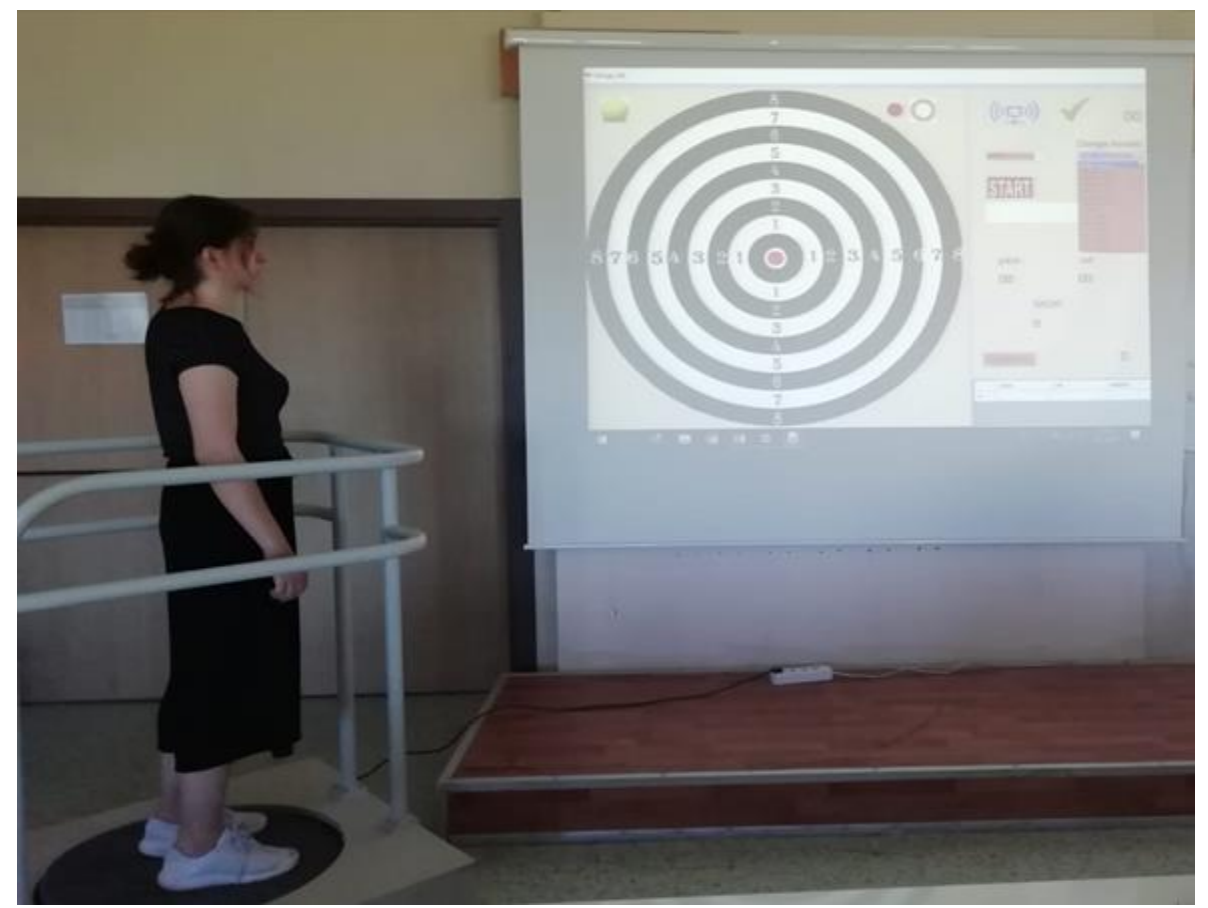

Şekil 6. Proprioseptif Duyuların Geliştirilmesi İçin Egzersiz ve Ölçüm Sistemi

\section{1 . Oyun Tabanlı Egzersizler}

Şekil 7'de Unity oyun motorunda tasarlanan Pacman ve Balon Patlama Oyunlarına ait bilgisayar arayüzleri görülmektedir. Oyunlar lateral düzlemde sağ ve sol hareket yapacak şekilde kolay seviye ve lateral ve frontal eksende sağ, sol, yukarı ve aşağı hareket yapacak şekilde zor seviye olmak üzere iki farklı şekilde tasarlanmıştır. Oyunda yapılan skorlar ve oyunu tamamlama süreleri kayıt edilerek gelişim süreci ölçüm sistemi ile birlikte buradan da takip edilebilmektedir.

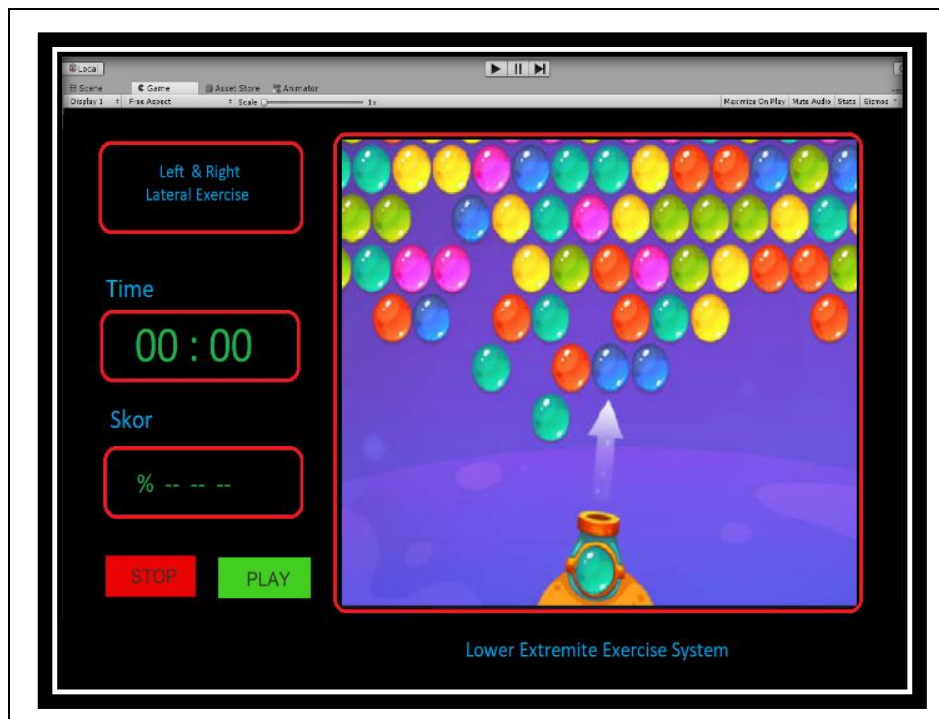

a) Balon Patlatma Oyunu

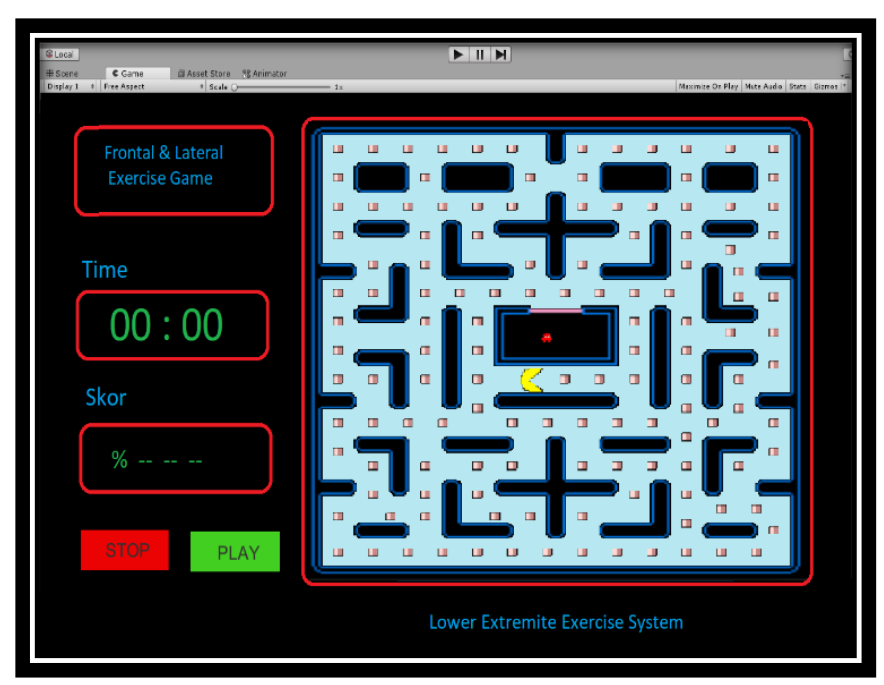

b) Pacman Oyunu

Şekil 7. Unity Oyun Motoru Arayüzler

\subsection{Gerçekleştirilen Sistemin Statik Denge Üzerindeki Etkisi}


Sağlıklı bir birey Tablo 1'deki egzersiz içeriği ve Şekil 5'deki uygulama takvimine göre çalıştırılmıştır. Geliştirilen sistem ile bireyin ağırlık merkezinin frontal ve lateral eksenlerindeki sapma açıları ölçülmüştür. Programın ilk başlanğıcında bireyin 30s test süresince frontal eksende $\pm 1^{\circ}$, lateral eksende $\pm 1^{\circ}$ salınım yaptığı görülmüştür. Egzersiz programı sonunda frontal ve lateral eksenlerdeki salınım tekrar ölçülmüsşür. Egzersiz sonunda yapılan statik denge ölçümleri Şekil 8a ve Şekil 8b'deki grafikte görülmektedir. Bireyin frontal eksende $\pm 0.2^{\circ}$, lateral eksende $\pm 0.03^{\circ}$ salınım yaptı̆̆ görülmüştür. Kişinin egzersiz öncesinde alınan ölçümlerinde frontal ve lateral eksenlerde ağırlık merkezinin saptığı görülmektedir. Belli bir program ile yapılan egzersiz sonrasında bu sapmaların azaldığı ölçümler ile görülmektedir.

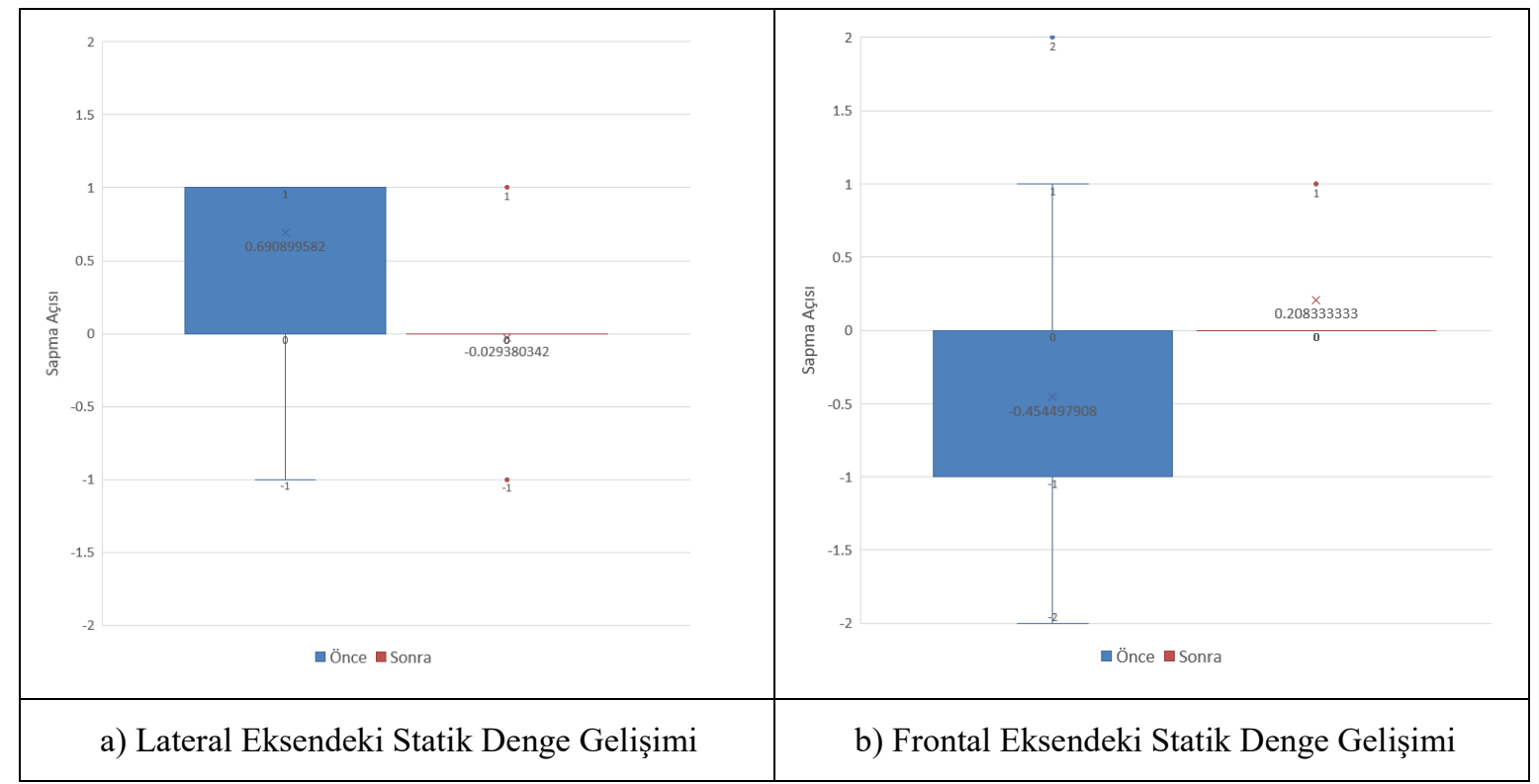

Şekil 8. Egzersiz Programının Statik Denge Üzerindeki Etkisi

\section{Sonuç}

Denge, vücudun sabit bir pozisyonda kalma yeteneği veya dış kuvvetlere karşı kararlı hareketler yapabilmesidir. Bir başka tanımla kişinin yerçekimi merkezinin algısal çerçevede dayanma alanı içerisinde tutabilmesidir. Denge yeteneğinin geliştirilmesi daha stabil alt ekstremite yaratarak daha kontrollü ve tutarlı hareketlerin yapılmasını sağlamaktadır. Alt ektremite stabilitesi ile ilgili birçok çalışma yapılmıştır. Bu çalışmalarda denge diskleri, yıldız denge testi, flamingo denge testi gibi testler uygulanarak statik ve dinamik denge durumlarına bakılmıştır. Bireyler vücudun dengesini görsel, verstibüler ve Proprioseptif sistemlerden alınan veriler ile sağlamaktadır. Kas, eklem ve tendonlarda vücudun ve uzuvların konumunun beyin tarafından algılanmasına yardımcı olan özel hücreler bulunmaktadır. Bu hücreler aynı zamanda bir kas veya eklem üzerindeki baskı ve kuvvet miktarı hakkında da beyine bilgi gönderirler. Proprioseptif sistem, beynin ne çeşit bir zeminde oturduğunu ya da vücudun nasıl konumlandığını anlamasına yardımcı olur. Görsel ve verstibüler sistemlerden gelen verilerde problem olması durumunda bu rahatsızlıklar klinik olarak giderilebilmektedir. Ancak kişinin kalıtsal özelliklerine bağlı olan Proprioseptif duyular yapılan egzersizler ile geliştirilebilmektedir. Bu çalışma diğer çalışmalardan farklı olarak ölçüm ve egzersiz sistemini bir araya getirerek proprioseptif duyuların yeterliliklerini ölçen ve egzersiz ile geliştirilmesini sağlamaktadır. Geliştirilen sistemden elde edilen veriler incelendiğinde sistemin güvenilir olduğu tespit edilmiştir. Ancak sistem geçerliliğinin belirlenmesi için kontrol ve test gruplarının oluşturulmasına ve tekrarlama testlerinin yapılması gereklidir. Sonuç olarak geliştirilen sistem ve egzersiz programının üst düzey denge ve hareketliliğe ihtiyaç duyan profesyonel sporcular veya herhangi bir rahatsızlık sonucunda fizik tedavi ve rehabilitasyona ihtiyaç duyulan hastalar için propriyoseptif duyuların yeterliliğini ölçemeye ve bu duyuların geliştirilmesine olanak sağlayacağı ön görülmektedir.

\section{Teșekkür}

$\mathrm{Bu}$ çalışmanın gerçekleştirilmesi için gereken altyapı desteğinden dolayı Afyon Kocatepe Üniversitesi Bilimsel Araştırma Projeleri Koordinatörlügü̆’ne teşekkür ederiz (18.Fen.Bil.43).

\section{Kaynakça}

Akseki, D., Erduran, M., Özarslan S., Pınar, H.,(2010). Patellofemoral ağrı sendromu saptanan hastalarda,dizde vibrasyon duyusu, propriosepsiyon duyusu ile paralel olarak algılanmaktadır: Pilot çalı̧̧ma. Eklem Hastalık Cerrahisi

Ateş, B., Çetin, E., Yarım, İ., (2017). Kadın Sporcularda Denge Yeteneği ve Denge Antrenmanları. Gaziantep Üniversitesi Spor Bilimleri Dergisi

Demir, A. ve Akın, M. (2018). Aktif Video Oyunları ve Wobble Board Denge Antrenmanının 6 Yaş Çocuklarda Dinamik Dengeye Etkisinin Karşılaştırılması. Gaziantep Üniversitesi Spor Bilimleri Dergisi, 3(4): 109- 121. 
Erdoğan, C.S., Er, F., İpekoğlu, G., Çolakoğlu, T., Zorba, E., Çolakoğlu, F.F., (2016). Farklı denge egzersizlerinin voleybolcularda statik ve dinamik denge performansı üzerine etkileri. Spor ve Performans Araş̧tırmaları Dergisi

İşler, K.A., (2007). Titreşimin performansa etkisi. Spor Bilimleri Dergisi, 18 (1): $42-56$

Fidan, U., Yıldız, M., Şahan, A., Gün, A., (2018). Development Of Static And Dynamic Equation In The Lower Extremity: Design And Verifying Of Game Based Exercise And Measurement Device. 9 Th International Biomechanics Congress

Kaynak, H., Altun, M., Özer, M., Akseki, D., (2015). Sporda Propriosepsiyon ve Sıcak - Soğuk Uygulamalarla İlişkisi. CBÜ Beden Ĕ̈itimi ve Spor Bilimleri Dergisi

Şahin, G., Şeker, H., Yeşilırmak, M., Çadır, A., (2016). Denge diski egzersizlerinin dinamik denge ve duruş kontrolü üzerindeki etkisinin incelenmesi. Spor ve Performans Araştırmaları Dergisi

Şimşek, D., Ertan, H., (2011). Postural Kontrol Ve Spor: Spor Branşlarına Yönelik Postural Sensör-Motor Stratejiler Ve Postural Salınım. SPORMETRE Beden Eğitimi ve Spor Bilimleri Dergisi, 2011, IX (3) 81-90 